\title{
Analysis of combustion, heat and fluid flow in a biomass furnace
}

\author{
Björn Pfeiffelmann ${ }^{1}$, Michael Diederich ${ }^{1}$, Fethi Gül ${ }^{1}$, Ali Cemal Benim ${ }^{1, *}$, Andreas Hamberger ${ }^{2}$ and Markus Heese $^{2}$ \\ ${ }^{1}$ Center of Flow Simulation (CFS), Dept. Mechanical and Process Engineering, Düsseldorf University of Applied Sciences, Germany \\ ${ }^{2}$ Endress Holzfeuerungsanlagen, Burgbernheim, Germany
}

\begin{abstract}
A waste wood burning boiler with $200 \mathrm{~kW}$ thermal power is investigated by experiments and numerically. Temperature measurements are performed in the furnace and in the heat exchanger sections in the downstream. Exit exhaust gas composition is also measured. Flow, heat transfer and combustion in the furnace, and forced convection on the water side are numerically analyzed. The water side calculations are used to obtain boundary conditions for the furnace by heat transfer coefficients. For validating the adopted mathematical/numerical formulation, the predictions are compared with measurements. A satisfactory agreement between the predictions and measurements is observed, confirming the validity of the applied computational procedures.
\end{abstract}

\section{Introduction}

Fossil fuels have been and are still being used as the major primary energy source for generation heat and of power [1-3]. For fossil fuels, the combustion process has been utilized for the conversion [4-8].

Parallel to the efforts for exploiting renewable energy sources [9], as well as recovery techniques [10-12], combustion continues to play an important role in power generation, also through the renewable energies, due to the significance of biomass in the latter [13-17]. Cogeneration is gaining importance as means of improving energy savings, where it is especially significant for decentralized systems, which is also an increasing trend in structuring future energy supply [1822].

The present manuscript presents the first step of a research project, which addresses biomass combustion, as well as cogeneration. The purpose of the project is the development of a waste wood burning boiler with a simultaneous generation of electric power via thermoelectric generators [11]. The purpose at this stage is developing a validated numerical procedure.

\section{The boiler}

The boiler is a wood fuel one with a thermal power of 200 $\mathrm{kW}$. The wood chips are transported by a screw at the furnace bottom. Primary air is injected into the bed of wood chips. The secondary air is injected as jets through a number of nozzles. The combustion products lose heat to boiler walls. To extract the remaining energy and feed this into the water, the gas is conducted through two passes of convective heat exchangers consisting of tubes with twisted tape fittings. The boiler structure is depicted in Figure 1.

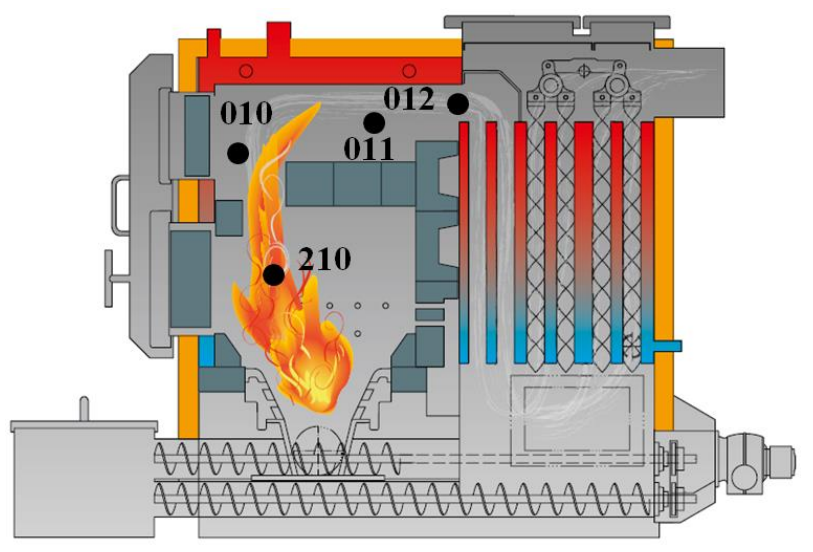

Fig. 1. Boiler schematic (indicating some measuring points)

\section{Models}

For simulations, the CFD code ANSYS Fluent 18.0 [23]. As Navier-Stokes solution procedure, the SIMPLEC [24] scheme is used. To numerically discretize the convective terms of the transport equations, a second-order upwind scheme is used [25]. Turbulence modelling strategy has been RANS (Reynolds Averaged Numerical Simulation) [26].

\subsection{Subdomains}

A challenge was the coupling between different subdomains. The water and gas domains are treated separately. The gas domain is also divided into two: the furnace, and the exhaust tract.

At inlets constant values are applied as boundary conditions for the variables. Turbulence quantities are estimated assuming turbulence intensity of $5 \%$, and the hydraulic diameter. At the inlet of the exhaust domain, the

\footnotetext{
* Corresponding author: alicemal@prof-benim.com
} 
furnace exit distributions are applied as boundary conditions. Static pressure is prescribed at outlets. For radiation, black surfaces are assumed at inlets and outlets.

Modelling the water domain, and the flow in the exhaust track, the Shear Stress Transport (SST) model $[23,27]$ is used, which was successfully applied to predict wall dominated turbulent flow and heat transfer, in many cases [28-31].

The modelling of the furnace sub-domain is most complex from the mathematical modelling point of view. The fuel is transported by a screw at the bottom of the furnace. From the side holes, primary and recirculating exhaust gas is injected into the fuel bed. The secondary air is injected by nozzles above the bed. The overall equivalence ratio is 0.5 [32]. It is assumed that the sole effect of primary air injection is a complete pyrolysis, where the latter burns above the bed. The inlet boundary is positioned above the bed, assuming a homogeneous gas composition.

For the furnace, the k- $\varepsilon$ turbulence model (the RNG version) is used [23,33], which is assumed convenient for the furnace flow with free shear layers. Radiation heat transfer [34] is important for the furnace domain. For its modelling, the Discrete Ordinates Model is used [23,35], which is known to be more accurate compared to P1 and similar approaches [36,37].

The gas absorption coefficient is calculated by the Weighted Sum of Gray Gases approach [23,38]. The ash particles are neglected in calculating the flow. Their effect on gas radiation properties is considered applying procedures described in [39], where the implementation was done by User Defined Functions [23].

Thermal boundary conditions at walls neighboring the water domain are prescribed using the heat transfer coefficients that are obtained from the calculation of the water domain and assuming an emissivity of 0.8 for gray walls. Internal walls that are exposed to gas on both sides are assumed to be adiabatic.

The fuel composition was obtained by elementary analysis. An analysis indicated that the pyrolysis products can be modelled as a mixture of $\mathrm{C}_{2} \mathrm{H}_{6}$ and $\mathrm{H}_{2}$. For its combustion, a three-step reaction mechanism is assumed, which is consisting totally of six chemical species $\left(\mathrm{C}_{2} \mathrm{H}_{6}\right.$, $\mathrm{H}_{2}, \mathrm{O}_{2}, \mathrm{H}_{2} \mathrm{O}, \mathrm{CO}, \mathrm{CO}_{2}$ ). To model the interaction of turbulence and chemical reaction the Eddy Dissipation Model [40] combined with Finite Rate chemistry (EDMFR) is used [23]. The chemical rate constants of the chemical kinetics are deduced from the references $[41,42]$.

\section{Experiments}

To validate the results of the numerical work, the boiler is analyzed experimentally. Mass flow rates of the primary air, the secondary air and the exhaust gas recirculation, as well as the corresponding velocity profiles, are measured with pitot tubes. The temperature in the furnace (suction pyrometer) and the heat exchanger (blank thermocouples) is measured. In total, the temperature is measured at 26 positions. Three positions in the furnace are indicated in Figure 1.

\section{Results}

A grid independence study was performed for all three parts, i.e. the furnace, the exhaust, and the water domains. An example of the grid independence study is shown in Figure 2.

The calculation is performed with $1.26,2.14,5.21$ million cells. The temperature varies between all three meshes less than $1 \%$. Thus the medium size grid is chosen as an acceptable compromise.

The validation of the temperature distribution by comparison with the experimental results obtained for the furnace is shown in Figure 3. Here, the measuring points are sorted in the downstream direction. One can observe that the present prediction and the experimental results show a quite good agreement, with a good overall accuracy. Comparisons of the temperatures between the experiments and the calculations in the exhaust track as well as in the water domain show a comparably well agreement.

The temperature distribution in the furnace is shown in more detail in Figure 4. Because of the continuing combustion reactions caused by the secondary air injection, the temperature rises and high temperatures occur in regions above secondary air jets. The flow direction caused by the drift can also be seen looking at the shape of the temperature pattern (Fig. 4). The mixture continues to react in the downstream parts of the boiler, and the conversion by combustion is completed before reaching the first pass of the convective tubular heat exchanger.

The measurements and calculations have shown that quite huge amounts of heat are transferred to the water, through the furnace walls, by convection and radiation, before the exhaust gas stream reaches convective, tubular hear exchangers on the downstream. This is also seen in the temperature distributions displayed in Figure 3 and Figure 4 that show a remarkable reduction of the gas temperature.

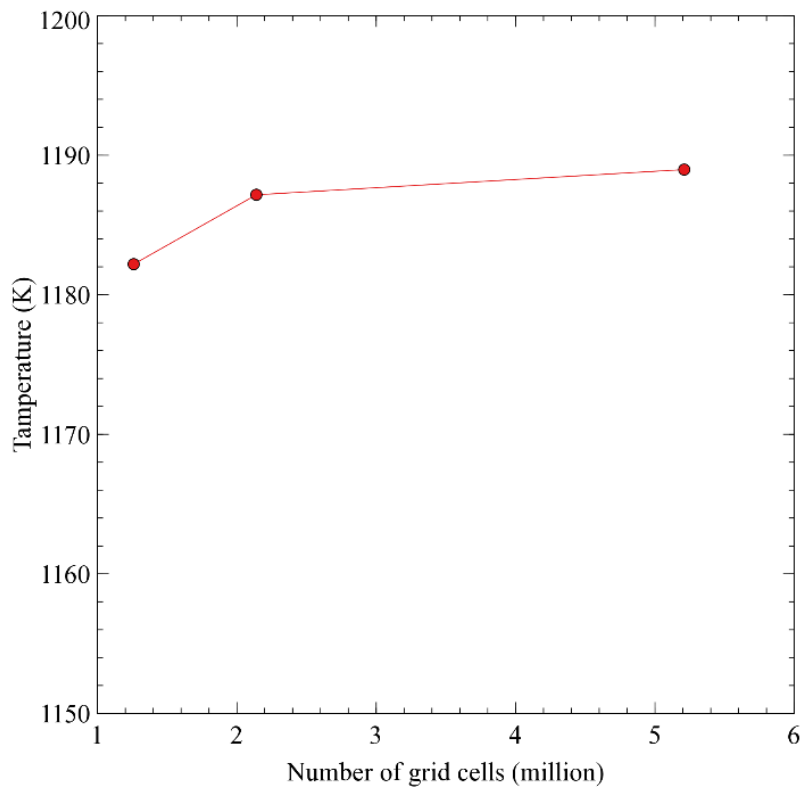

Fig. 2. Grid independence study for the furnace (point 010) 


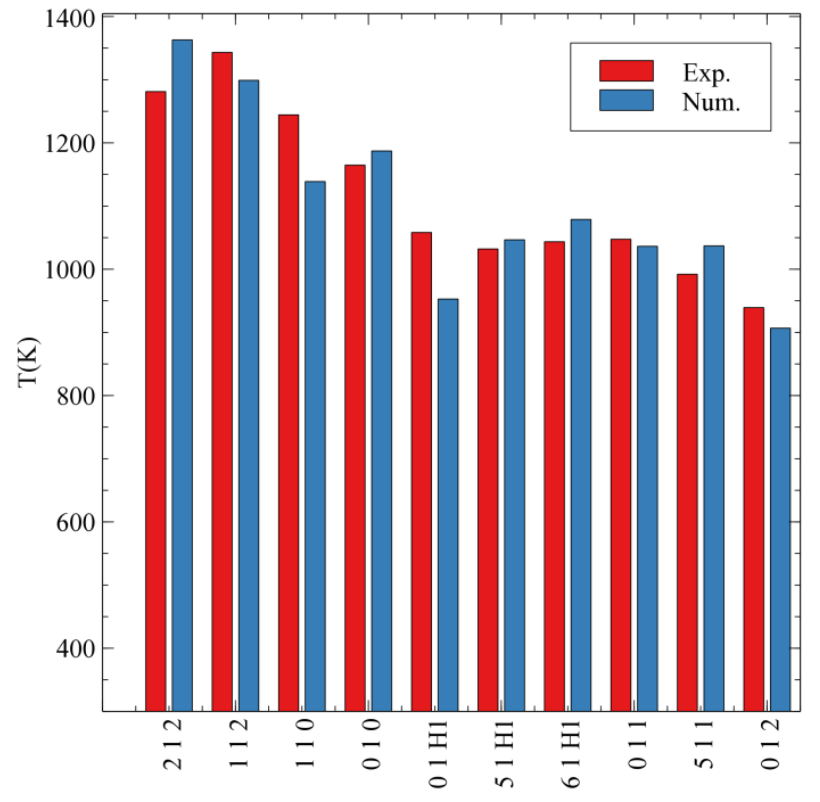

Fig. 3. Validation of the temperature distribution in the furnace

$[\mathrm{K}]$

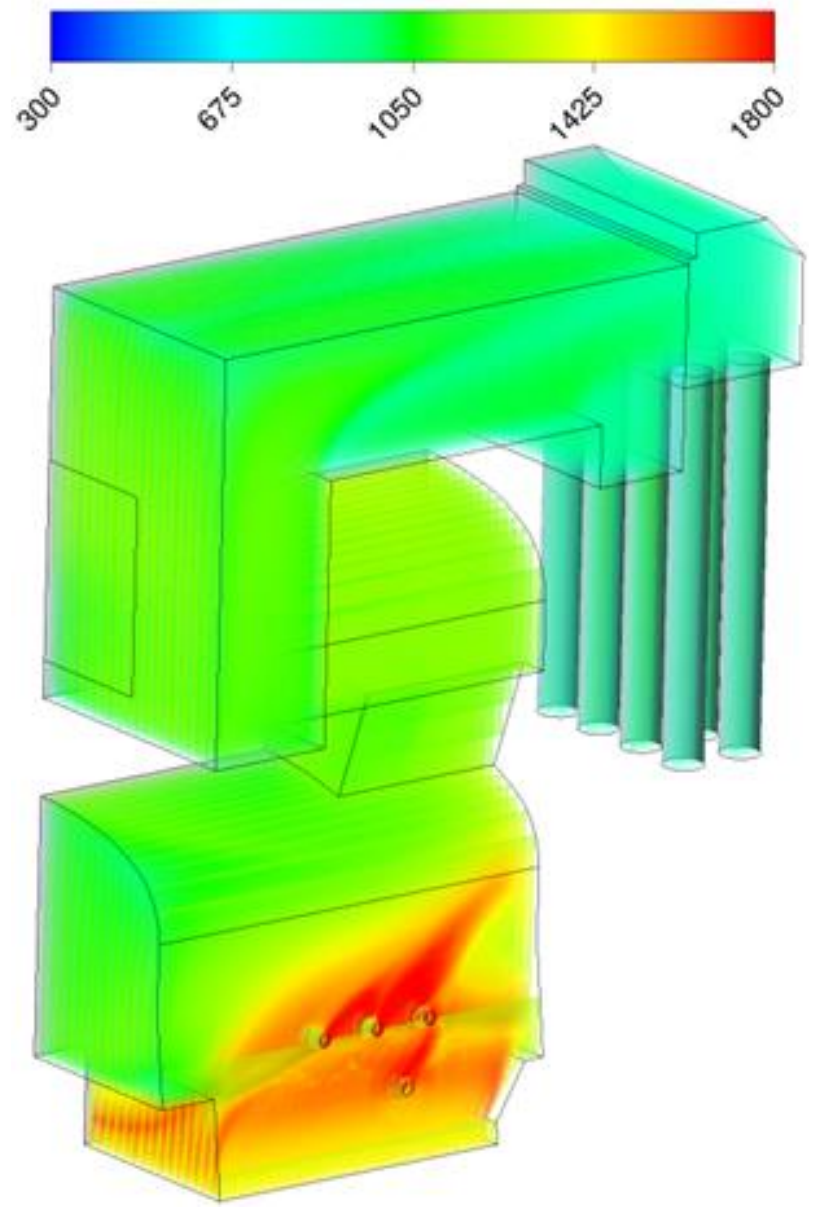

Fig. 4. Predicted temperature (in K) distribution of the furnace

The predicted temperature field in the both passes of the convective heat exchanger is shown in Figure 5. The distribution of the heat transfer coefficient on the outer surfaces of the tubes and the flow pattern in the water side are displayed in Figure 6.
$[\mathrm{K}]$

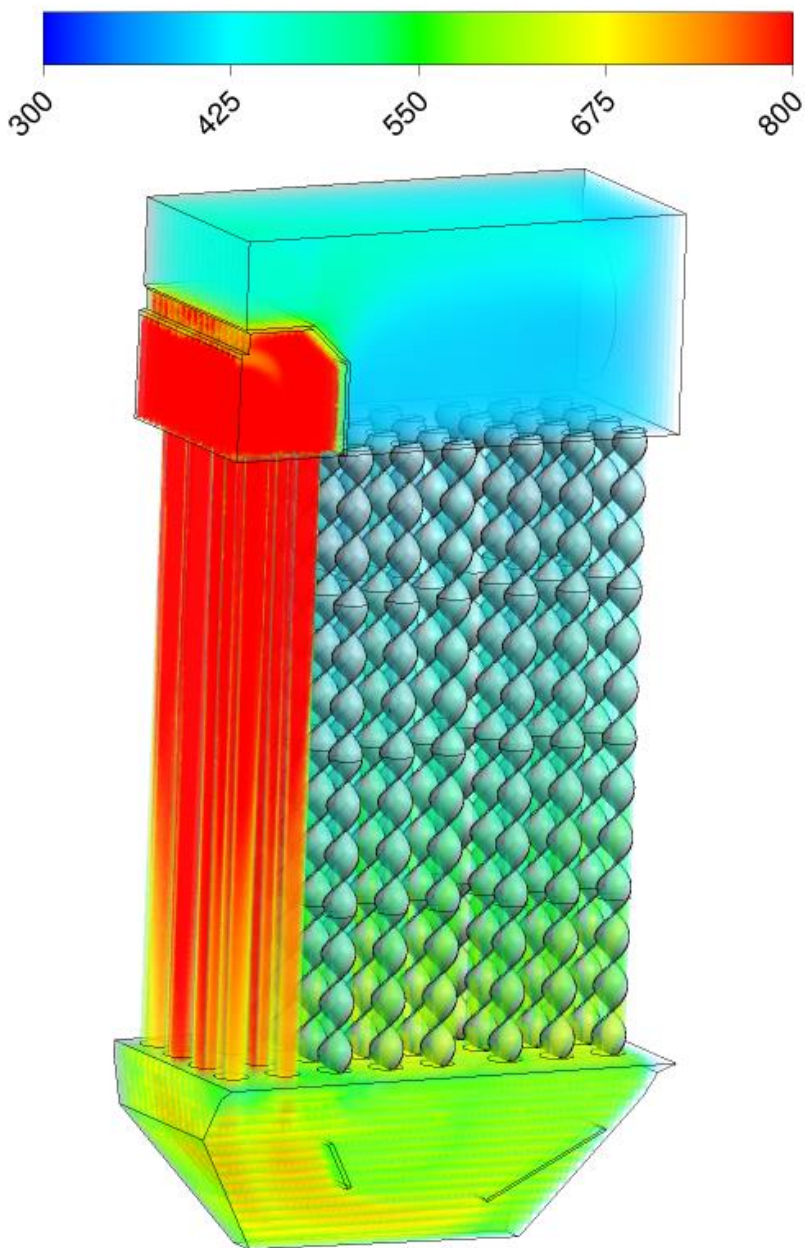

Fig. 5. Predicted temperature distribution of the exhaust track

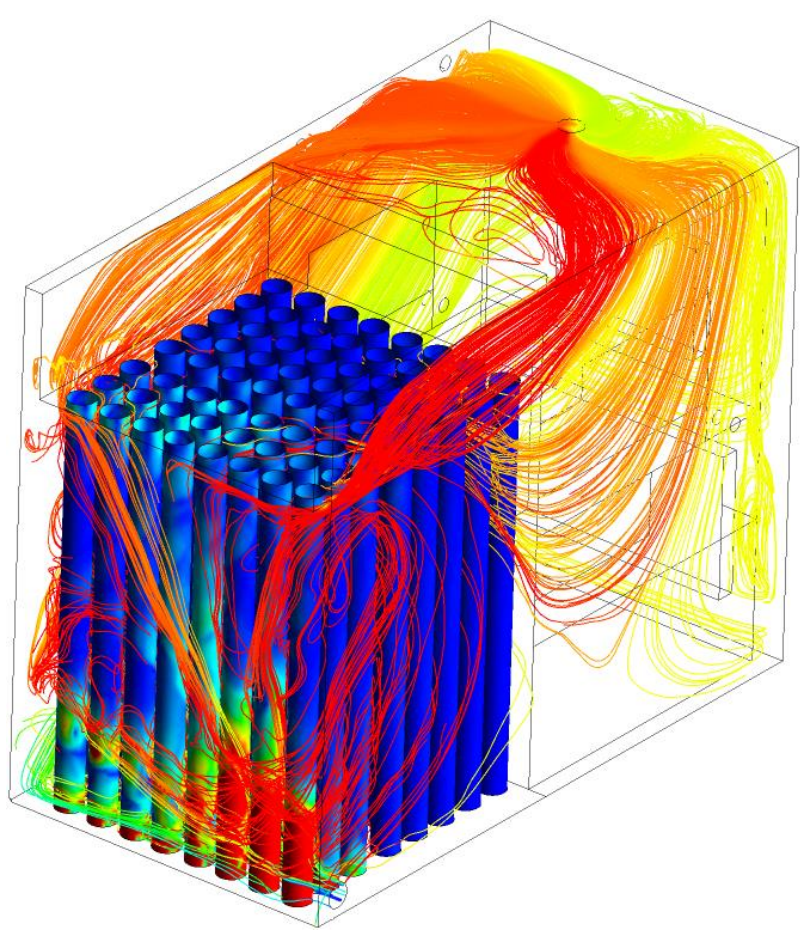

Fig. 6. Predicted heat transfer coefficient at the cylinder walls and streamlines inside the water domain 


\section{Conclusion}

A waste wood combusting boiler with $200 \mathrm{~kW}$ thermal power is analyzed. The numerical domain was divided into three sections, the furnace, the exhaust, and the water domains. It was observed that the prediction and the measurements show a quite good agreement.

We gratefully acknowledge the financial support by the German Federal Ministry of Economy and Energy.

\section{References}

1. P. Breeze, Power Generation Technologies, $2^{\text {nd }}$ Ed. (Newnes, Oxford, 2014)

2. R. Wiltshire, Advanced District Heating and Cooling (DHC) Systems, $2^{\text {nd }}$ Ed. (Woodhead Publishing, Cambridge, 2016)

3. A.C. Benim, M. Geiger, S. Doehler, $M$. Schoenenberger, H. Roemer, "Modelling the flow in the exhaust hood of steam turbines under consideration of turbine-exhaust hood interaction", in: Proceedings 1st European Conference Turbomachinery - Fluid Dynamic and Thermodynamic Aspects: Computational Methods, Erlangen, Germany, March 1-3, 1995, Book Series: VDI Berichte, Vol.1185, pp.343-357 (VDI Verlag, Duesseldorf, 1995)

4. A.C. Benim, B. Epple, B. Krohmer, "Modelling of pulverised coal combustion by a Eulerian-Eulerian two-phase flow formulation", Progress in Computational Fluid Dynamics - An International Journal, 5(6), pp.345-361 (2005)

5. J.P. Kim, U. Schnell, G. Scheffknecht, A.C. Benim, „Numerical modelling of MILD combustion for coal", Progress in Computational Fluid Dynamics An International Journal, 7(6), pp.337-346 (2007)

6. A.C. Benim, K.J. Syed, Flashback Mechanisms in Lean Premixed Gas Turbine Combustion, (Academic Press, Cambridge, MA, USA, 2014)

7. A.C. Benim, M.P. Escudier, A. Nahavandi, A.K. Nickson, K.J. Syed, F. Joos, "Experimental and numerical investigation of isothermal flow in an idealized swirl combustor", International Journal of Numerical Methods for Heat \& Fluid Flow, 20(3), pp.348-370 (2010)

8. A.C. Benim, S. Iqbal. W. Meier, F. Joos, A. Wiedermann, "Numerical investigation of turbulent swirling flames with validation in a gas turbine model combustor", Applied Thermal Engineering, 110, pp.202-212 (2017)

9. R. Ehrlich, Renewable Energy (CRC Press, Boca Raton, 2013)

10. E. DuBois, A. Mercier (Ed.), Energy Recovery (Nova Science Publishers, NY, 2009)

11. D.G. Ebling, A. Krumm, B. Pfeiffelmann, J. Gottschald, J. Bruchmann, A.C. Benim, M. Adam, R. Labs, R. R. Herbertz, A. Stunz, "Development of a system for thermoelectric heat recovery from stationary industrial processes", Journal of Electronic Materials, 45(7), pp.3433-3439 (2016)

12. S. Fan, Y. Gao, "Numerical analysis on the segmented annular thermoelectric generator for waste heat recovery", Energy, 183, pp.35-47 (2019)

13. M. Kaltschmitt (Ed.), Energy From Organic Materials (Biomass) (Springer, New York, NY, USA, 2019)

14. A. Eric, S. Nemoda, M. Komatina, D. Dakic, B. Repic, "Experimental investigation on the kinetics of biomass combustion in vertical tube reactor", Journal of the Energy Institute, 92(4), pp.1077-1090 (2019)

15. B.G. Mustafa, M.H.M. Kiah, A. Irshad, G.E. Andrews, H.N. Phylaktou, H. Li, B.M. Gibbs, "Rich biomass combustion: gaseous and particle number emissions", Fuel, 248, pp. 221-231 (2019)

16. C. Chen, Z. Luo, C. Yu, "Release and transformation mechanisms of trace elements during biomass combustion", Journal of Hazardous Materials, 380, Article 120857 (2019)

17. T. Chen, X. Ku, J. Lin, H. Jin, "Modelling the combustion of thermally thick biomass particles", Powder Technology, 353, pp. 110-124 (2019)

18. M. Pehnt, M. Cames, C. Fischer, B. Praetorius, L. Schneider, K. Schumacher, J.-P. Voß, Micro Cogeneration (Springer, Berlin, Germany, 2006)

19. J. Kalina, M. Swierzewski, R. Strzalka, „Operational experiences of municipal heating plants with biomass-fired ORC cogeneration units", Energy Conversion and Management, 181, pp. 544-561 (2019)

20. R. Strzalka, T.G. Erhart, U. Eicker, „Analysis and optimization of a cogeneration systedm based on biomass combustion, Applied Thermal Engineering, 50(2), pp.1418-1426 (2013)

21. J. Kalina, N. Swierzewski, „Identification of ORC unit operation in biomass-fired cogeneration system“, Renewable Energy, 122, pp.400-414 (2019)

22. N. Mahdavi, S. Khalilarya, „Comprehensive thermodynamic investigation of three cogeneration systems including GT-HRSG/RORC as the base system, intermediate system and solar hybridized system“, Energy, 181, pp.1252-1272 (2019)

23. ANSYS $®$ FLUENT, www.ansys.com

24. J.P. van Doormaal, G.D. Raithby, "Enhancements of the simple method for predicting incompressible fluid flows", Numerical Heat Transfer, 7,pp.147-163 (1984)

25. T.J. Barth, D.C. Jespersen, "The design and application of upwind schemes on unstructured meshes", AIAA-89-0366 (1989)

26. P.A. Durbin, B.A. Pettersson Reif, Statistical Theory and Modeling for Turbulent Flows (Wiley, Chichester, UK, 2003)

27. F.R. Menter, "Two-equation eddy viscosity turbulence models for engineering applications", AIAA Journal, 32, pp. 1598-1605 (1994) 
28. F. Menter, J.C. Ferreira, T. Esch, B. Konno, "The SST turbulence model with improved wall treatment for heat transfer predictions in gas turbines", Proc. International Gas Turbine Congress, IGTC2003-TS059, Tokyo, 2-7 November (2003)

29. Z. Tao, Z. Cheng, J. Zhu, L. Haiwang, "Effect of turbulence models on predicting convective heat transfer to hydrocarbon fuel at supercritical pressure", Chinese Journal of Aeronautics, 29(5), pp.1247-1261 (2016)

30. M.A.R. Sharif, K.K. Mothe, "Evaluation of turbulence models in the prediction of heat transfer due to slot jet impingement on plane and concave surfaces", Numerical Heat Transfer, Part B: Fundamentals, 55(4), pp.273-294 (2009)

31. F.A.Z.M. Saad, A.J. Jaworski, "Numerical predictions of early stage turbulence in oscillatory flow acoss parallel-plate heat exchangers of a thermoacoustic system", Applied Sciences, 7, 673 (2017)

32. S.R. Turns, An Introduction to Combustion, $3^{\text {rd }}$ ed., (McGrawHill, New York, USA, 2012)

33. T.J. Shih, W.W. Liou, A. Shabbir, Z. Yang, J. Zhu, 1995. "A new k- $\varepsilon$ model for high Reynolds number turbulent flows - Model development and validation", Computers and Fluids, 24(3), pp-227-238 (1995)

34. M.N Özisik, Radiative Transfer and Interactions with Conduction and Convection (Wiley, NY, 1973)

35. E.H. Chui, G.D. Raithby. "Computation of Radiant Heat Transfer on a Non-Orthogonal Mesh Using the Finite-Volume Method", Numerical Heat Transfer, Part B, 23, pp.269-288. (1993)

36. R. Siegel, J.R. Howell, Thermal Radiation Heat Transfer (Hemisphere, Washington DC, 1992)

37. A.C. Benim, "A finite element solution of radiative heat transfer in participating media utilizing the moment method", Computer Methods in Applied Mechanics and Engineering, 67(1), pp.1-14 (1988)

38. P.B. Taylor, P.J. Foster, "The total emissivities of limunous and non-limunous flames", International Journal of Heat and Mass Transfer, 17(12), pp. 15911605 (1974)

39. Verein Deutscher Ingenieure, „VDI-Wärmeatlas“, Springer, DOI: 10.1007/978-3-642-19981-3 (2013).

40. B.F. Magnussen, G.H. Hjertager, „On mathematical modelling of turbulent combustion with special emphasis on soot formation and combustion", Proceedings of the 16th Symposium (International) on Combustion, pp. 719-729, The Combustion Institute, Pittsburgh, USA.

41. C.K. Westbrook, F.L. Dryer, "Simplified Reaction Mechanisms for the Oxidation of Hydrocarbon Fuels in Flames", Combustion Science and Technology, 27, pp. 31-43 (1981)

42. A. Brink, „Eddy Break-Up Based Models for Industrial Diffusion Flames with Complex Gas Phase Chemistry, Ph.D Thesis, ABO Akademi University, Finland 